\title{
Combination therapy of low-dose cidofovir and leflunomide in a kidney transplant recipient with BK virus nephropathy: a case report
}

Tae Hyun Ryu, Hee yeoun Kim, Joon Seok Oh, Joong Kyung Kim

Department of Internal Medicine-Nephrology, Bongseng Memorial Hospital, Busan, Korea

Background: BK virus frequently results in allograft loss or permanent dysfunction in kidney transplant recipients. It is a challenge to treat BK virus nephropathy (BKVN) because the reduction of immunosuppression for the treatment of BKVN can increase. Thus the treatment of BKVN has been not well established. Cidofovir is a nucleotide analog against various DNA viruses and was approved for the treatment of cytomegalovirus retinitis in AIDS. The main side effect of cidofovir is nephrotoxicity and it is dose dependent. Several cases have been reported that combination of cidofovir and leflunomide was used for refractory BKVN. However it remains as a dilemma for BKVN treatment because of the nephrotoxicity of cidofovir. Thus we report a case that refractory BKVN to reduction of immunosuppression was successfully treated by combination therapy of low-dose cidofovir and leflunomide in a kidney transplant recipient.

Case report: A 63-year-old male receiving kidney transplant before 6 months was hospitalized due to elevated serum creatinine. He was taking immunosuppressive agents; tacrolimus, mycophenolate mofetil and prednisolone. At 6 months of post transplantation, serum creatinine increased to $2.7 \mathrm{mg} / \mathrm{dL}$. Allograft biopsy was performed and it was compatible with BKVN. BK viral loads (DNA) at admission were 291,250 copies/mL in blood and 195,498,400 copies/mL in urine. Tacrolimus and mycophenolate mofetil were switched to leflunomide (40 mg/day). However, serum creatinine continuously elevated to $4.2 \mathrm{mg} / \mathrm{dL}$ with increase of viral loads (546,000 in blood and 785,000,000 copies/mL in urine). Low-dose of cidofovir $0.25 \mathrm{mg} / \mathrm{kg}$ was intravenously administered weekly for 4 weeks. At 4 weeks with combination therapy of low-dose of cidofovir and leflunomide, viral load decreased to 4,915 copies $/ \mathrm{mL}$ in blood and $70,000,000$ copies $/ \mathrm{mL}$ in urine and serum creatinine decreased to $2.2 \mathrm{mg} / \mathrm{dL}$.

Conclusions: Combination therapy of low-dose cidofovir and leflunomide can be considered in a kidney transplant recipient with BKVN.

Corresponding author: Tae Hyun Ryu

E-mail: neo13@hanamil.net

(c) The Korean Society for Transplantation

This is an Open Access article distributed under the terms of the Creative Commons Attribution Non-Commercial License (http://creativecommons.org/licenses/by-nc/4.0/) which permits unrestricted non-commercial use, distribution, and reproduction in any medium, provided the original work is properly cited. 